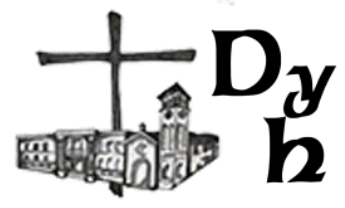

\title{
LOS PAPAS Y DANTE
}

The Popes and Dante

\author{
Adriana Rogliano \\ arogliano@gmail.com \\ Investigadora independiente - La Plata - Argentina
}

\section{Resumen}

La figura del "sumo poeta" como hombre de letras e hijo de la Iglesia, no fue indiferente a los Papas, quienes no tardaron en reconocer el estrecho vínculo entre su poesía y el contenido evangélico. Toda una tradición se descubre al respecto, no sólo para ensalzarlo como vate sino también como creyente. Es así como a partir de Benedicto XV hasta Francisco, los Pontífices celebraron cada señalado aniversario de su nacimiento y muerte con algún homenaje particular o un documento específico, teniendo en cuenta las circunstancias históricas que les eran propias.

Palabras claves: Dante - Papas - Centenario

\section{Abstract}

The figure of the "supreme poet" as a man of letters and son of the Church, was not indifferent to the Popes, who did not take long to recognize the close link between his poetry and the evangelical content. A whole tradition is discovered in this regard, not only to praise him as a vate but also as a believer. This is how from Benedict XV until Francis, the Pontiffs celebrated each marked anniversary of his birth and death with a particular tribute or a specific document, taking into account the historical circumstances that surrounded them.

Keywords: Dante- Popes - Century 


\section{Introducción}

Con la carta apostólica Candor lucis aeternae, el papa Francisco ha querido conmemorar el séptimo centenario de la muerte de Dante Alighieri. Como él mismo nos lo recuerda, se trata de un acontecimiento que, además de involucrar a estudiosos de todo el orbe, desde un siglo a esta parte, y tras el reconocimiento hecho por Benedicto XV de la esencial pertenencia del poeta al pensamiento cristiano, convoca a los sucesivos pontífices, a hacerse presentes mediante variados escritos. Como resultado de este interés entusiasta y perseverante, dichos documentos han ido descubriendo facetas antes no observadas de la Divina Comedia a la luz del devenir temporal y de la problemática que ello conlleva. En cada efeméride también puede apreciarse por parte de los papas —además de la realización de diversos homenajes en que se llama a los creyentes a la activa participación-, la recomendación, fervorosa e insistente, dirigida al estudiantado del ámbito de las letras y de las artes a una frecuentación más proficua de la obra del Sumo Poeta.

Habiendo expuesto su propia interpretación, el papa Francisco nos invita a acercarnos a la magna obra con el mismo oído atento con que fue seguida en el pasado, a la vez que estimula su divulgación a través de los medios tecnológicos del presente, y espera que la misma pueda seguir inspirando a literatos, artistas y músicos a comunicar las verdades más profundas y producir mediante los diversos lenguajes artísticos, por la vía de la belleza, frutos de "paz, libertad y fraternidad".

\section{Breve semblanza del "Summo Poeta"}

Dante Alighieri (Durante di Alighiero degli Alighieri), poeta, lingüista, filósofo y teórico político, nació en Florencia en $1265 .^{1}$ Hijo mayor de Alighiero di Bellincione - hombre de negocios - y poseedor de una situación económica holgada $^{2}$ se dedicó a los estudios de gramática y filosofía — quizá con los

\footnotetext{
${ }^{1}$ No poseemos un retrato suyo realizado en vida. El más antiguo es el atribuido a Giotto (ca. 1314) en la Capilla del Palazzo del Bargello (Actual Museo Nacional del Bargello), y descubierto en 1800, aunque el más conocido es el realizado por Sandro Botticelli en 1495.

2 Dante, según narra en la Commedia, descendía a Cacciaguida degli Elisei (1091-1148), quien participó de la segunda cruzada encabezada por el emperador Conrado III (1093-1152) y fue hecho caballero y finalmente murió martirizado en Tierra Santa. Su abuelo y su padre, en cambio, se habían ocupado de negocios financieros, acumulando la riqueza que le permitió dedicarse permanentemente al estudio, comprar los costosos libros y viajar.
} 
franciscanos del convento de la Santa Cruz- y retórica con Brunetto Latini ${ }^{3}$ y luego en la universidad de Bolonia (1286-1287) donde se piensa que habría seguido diversos cursos. ${ }^{4}$ Siendo muy joven formó parte del grupo de poetas cultores del dolce stil novo, ${ }^{6}$ como se muestra en La vita nuova, obra de carácter autobiográfico en la que aúna poesía y prosa y donde aparece por primera vez la figura de Beatriz. ${ }^{7}$

Dante no desdeñó participar como soldado güelfo en el sitio de Poggio di Santa Cecilia contra los aretinos (1285) y en la batalla de Campaldino (1289) por la que Florencia logró la hegemonía sobre todas las ciudades toscanas.

En 1290 muere tempranamente su amada Beatriz y el poeta perturbado y confundido atraviesa una crisis personal que le lleva a buscar consuelo en los estudios de filosofía.

Luego, en fecha no bien establecida, se casa con Gemma Donati ${ }^{8}$ con quien se le había desposado a los doce años.

Hacia 1295, el poeta comienza a interesarse por participar en política. Por entonces el poder estaba en manos del denominado "Governo del popolo", (gobierno popular) integrado por los representantes del estamento burgués -industriales y artesanos, empresarios grandes y pequeños - que pagaba los impuestos y defendía sus intereses económicos, desplazando a sus sempiternos rivales, los nobles o magnates, permanentemente dispuestos a irrumpir con

\footnotetext{
${ }^{3}$ Notario, filósofo y político florentino de noble origen (1220 - 1294 o 1295). De militancia güelfa, exilado se refugió en Francia donde escribió La llave del tesoro. Tradujo por vez primera la Ética a Nicómaco, de Aristóteles y De inventione, de Cicerón. En 1273 fue rehabilitado y a partir d entonces retomó la carrera política en Florencia, siendo electo Prior en 1287. En la última etapa de su agitada vida se dedicó a la enseñanza de la retórica y la oratoria teniendo por discípulos a D. y a su amigo el poeta Guido Cavalcanti.

${ }^{4}$ Su hijo Jacopo escribió que allí D. había estudiado astronomía.

${ }^{5}$ El médico e historiador Orlando Mejía Rivera, infiere que Dante hubiera estudiado en la facultad de Medicina con Tadeo Alderotti —ilustre médico florentino que se ocupó de semiología y fue de los primeros en recomenzar con la disección-a quien menciona en la Commedia (Paraíso, XII, 82-85) y en Convivio $(1, \mathrm{X}, 10)$.

${ }^{6}$ Nombre del movimiento poético generalizado en Toscana entre la segunda mitad del siglo XIII y principios del XIV. Su material poético era, ante todo, la meditación sobre el amor, su esencia filosófica y sus efectos psicofisiológicos y morales.

${ }^{7}$ Identificada como Bice di Folco Portinari, casada con Simone de' Bardi y fallecida el 8 junio de 1290.

${ }^{8}$ Hija de Manetto dei Donati, nacida en torno 1265 y muerta en 1343, perteneciente a una rama menor de los Donati. De este matrimonio nacen varios hijos de entre los cuales se encuentran: Giovanni, lacopo, Pietro y Antonia.
} 
violencia en la escena comunal $^{9}$ y a quienes Giano della Bella, gonfaloniero de justicia entre 1293 y el 1295, mediante un nuevo ordenamiento, se había encargado apartar.

Dante se inscribió formalmente en la corporación de los médicos y boticarios. ${ }^{10}$ Fue así como, alineado con la facción blanca del partido güelfo, ${ }^{11}$ llegó a integrar varios organismos consultivos, en los que solía defender posiciones moderadas tendientes a la pacificación. En la cúspide de su carrera política, Dante es elegido Prior, cargo que ocupó entre junio y agosto de $1300^{12}$ y cuyo ejercicio no estaba exento de riesgos en aquel tiempo de crueles enfrentamientos, tanto es así que durante su mandato, los priores eran alojados en una torre para protegerlos de cualquier posible atentado.

En 1301, Dante fue enviado a Roma en calidad de embajador de la Signoria para tratar con el Papa Bonifacio VIII la cuestión de las libertades comunales, siendo allí retenido. Entre tanto, con el fin declarado de restablecer la paz, aquel papa envió al príncipe Carlos de Valois, ${ }^{13}$ escoltado por los güelfos negros. Esta facción, aprovechando la circunstancia, no tardó en consumar un golpe de estado, matando a la mayor parte de sus enemigos - los blancos- y saqueando y destruyendo sus propiedades. En consecuencia, la casa y los bienes de Dante fueron arrasados y a él, junto con otros notables de su partido, se le inició un proceso jurídico en el que se les acusaba de una larga serie de

\footnotetext{
${ }^{9}$ Véase la conferencia de A. Barbero, Dante e il potere -Florencia, 16/10/20 - para RaiPley.

${ }^{10}$ Véase nota 5. El Dr. O. Mejía Rivera, se detiene en este hecho y aclara que, para ser aceptado en esa corporación, el candidato debía someterse a examen "de los tratados clínicos conocidos de Hipócrates, Galeno, Dioscórides, algunos capítulos del Canon de Avicena, fragmentos de las traducciones de Averroes y otros provenientes de los profesores de la Escuela de Salerno", obras estas — fuera del texto hipocrático-, sumamente especializadas y, por tanto, desconocidas por un humanista.

11 Recordemos que, en la atormentada vida política de aquel tiempo, dos partidos irreconciliables se enfrentaban en Italia: los Güelfos — partidarios del papa-y los Gibelinos secuaces del emperador-. Los primeros, disputándose el control del poder municipal se dividieron, a su vez, en Blancos y Negros. Dante simpatizaba con los blancos encabezados por los Cerchi, ricos banqueros, enfrentados con los Donati, de noble prosapia, parientes de la mujer de Dante.

${ }^{12}$ El cargo tenía esa exigua duración a causa del estado de revulsión política imperante en aquella ciudad.

13 Este príncipe (1270 y 1325), tercer hijo de Felipe III de Francia y hermano de Felipe IV el hermoso, que se dirigía a tomar Sicilia, fue desviado por el papa a Florencia.
} 


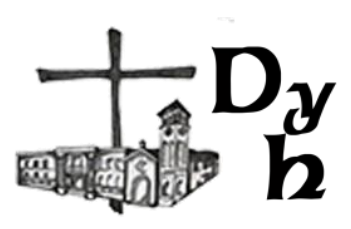

infamantes delitos fue condenado a pagar una costosa multa. Avisado de los acontecimientos, Dante no entró en la ciudad, y por no haberse presentado fue expulsado bajo pena de muerte.

Esto marcó el inicio del largo peregrinaje del poeta a través de diversos estados italianos, desposeído de su familia, de sus bienes y de su patria. ${ }^{14}$

En 1315, Florencia decidió promulgar una amnistía para los desterrados, pero las condiciones eran extremadamente duras: si Dante volvía, debía hacerlo vistiendo saco de penitente, además de reconocer públicamente su culpabilidad y pagar una importante multa. En la Carta a un amigo florentino, ${ }^{15}$ el bardo comenta así la resolución:

¿Es esta la revocación graciosa con la cual se invita a Dante Alighieri a que vuelva a su patria después de haber padecido un destierro de casi tres lustros? ¿Es esto lo que ha merecido su inocencia manifiesta a todas las gentes? ¿Es esto el fruto de tantos sudores y continuos trabajos dedicados al estudio? ¡No es digna de un hombre familiarizado con la filosofía una bajeza de espíritu que le haga tolerar [...] un regreso a Florencia como un traidor!

Y agrega más adelante:

¿Acaso no podré yo contemplar en cualquier sitio del mundo el cielo con el sol y las estrellas? ¿O es que podré buscar, bajo cualquier cielo la dulcísima verdad sin tener primero que regresar a Florencia lleno de deshonra, más aún, de ignominia, ante los ojos de mis conciudadanos? No lo dudéis: el pan no me faltará (1994, p. 812).

La reacción del gobierno florentino no se hizo esperar: la condena a muerte es refrendada nuevamente y esta vez alcanza también a sus hijos adolescentes.

\footnotetext{
${ }^{14}$ Las costumbres de la época consagraban la intolerancia respecto de los adversarios políticos. Lo novedoso en este caso fue la incoación de un proceso jurídico que, aunque político, se mostraba técnicamente correcto.

${ }^{15}$ Se trataría de un religioso, cuñado suyo, conocido como Ferruccio de Manetti Donati.
} 
Por veinte años intentó, vanamente y por diversos medios, retornar a su patria y recobrar la perdida ciudadanía florentina. Fue en este período que compuso el grueso de su obra, que comprende, además de la Commedia, tratados de lingüística, filosofía, y política.

Al volver de una misión diplomática en Venecia, encomendada por el señor de Ravena, Dante muere de improviso, la noche del 13 al 14 de septiembre de $1221 .^{16}$

Con el tiempo, Florencia lamentó aquel penoso destierro.

Reabierto el proceso en su contra, el poeta fue formalmente rehabilitado por las autoridades comunales florentinas en el año $2008 .^{17}$

\section{La composición de la Commedia}

Las circunstancias históricas y la finalidad de la obra

Según lo escrito por Giovanni Boccaccio, los primeros siete cantos de la Commedia hubieron sido compuestos en Florencia, con anterioridad al exilio y, guardados por su mujer, se los habrían hecho llegar a su residencia en Lunigiana, aunque la veracidad de esta información es discutida. Lo cierto es que Dante daba a conocer los cantos de la Commedia en la medida que los iba creando. ${ }^{18}$ De la publicación del Infierno nos lo hace saber Francesco di Barberino, comentando la existencia de la obra en 1215, en tanto que el Purgatorio habría sido difundido entre 1314 y 1315 . Hay noticias de la existencia de copias manuscrtias del Infierno en torno al 1313.

La composición del Paraíso, iniciada en 1316, ocuparía los últimos años de la vida de Dante que lo divulgaba, poco a poco, excepto los tres últimos cantos. ${ }^{19}$ Muerto el poeta, todo hacia pensar a sus lectores que la magna obra

\footnotetext{
${ }^{16}$ Se conjetura que en Venecia pudo haber contraído malaria.

${ }^{17}$ La reapertura del proceso, promovida por los descendientes de Dante —entre los cuales se cuenta el astrofísico Sperello di Serego Alighieri- se realizó en presencia de su vigésimo nieto y jefe dinástico, el conde Pieralvise Serego Alighieri, y el descendiente de su acusador, Cante dei Gabrielli da Gubbio, Antoine de Gabriele.

18 La publicación consistía en el dar a conocer un texto y permitir que los copistas lo reprodujeran, en papel, para la comunidad internacional interesada en las letras.

19 Lamentablemente se carece de la redacción autógrafa. La misma fue inútilmente buscada hasta la actualidad, de lo cual da testimonio el descendiente de Dante Conde Pieralvisi Serègo Alighiri, quien también hizo un intento.
} 


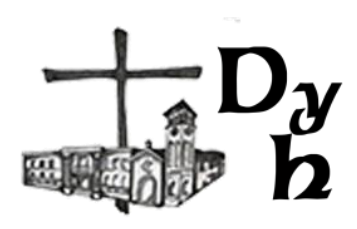

habría quedado inconclusa y hasta sugerían que fuera retomada por los hijos. Pero, algunos meses despúes, su hijo Jacopo encotró aquellos cánticos y los propagó enviándolos al Señor de Ravenna, también poeta, y admirador de Dante. $^{20}$

Que la Commedia representaba para el vate la coronación de su obra lo atestigua la presentación que de ella hace en la Carta $X I^{21}$ y el cuidado que le mereció durante los muchos años de su largo destierro. Dante construía un poema doctrinal en que habría de resumirse toda la concepción del mundo, de la vida y de la trascendencia según el ideal del opus consummatum; esto es, una síntesis de conocimiento (sapientia) y perfección expresiva (eloquentia). ${ }^{22} \mathrm{El}$ espíritu del poeta, iluminado por el quadrivium y adornado por el trivium, ponía en juego toda su capacidad creadora. $Y$ todo ello es logrado por Dante mediante el arte, que como bien se dirá, "abstrae y concentra, es decir sorprende la esencia ideal característica tanto en los hombres como en las cosas, y luego la representa" (Pirandello, 1994, p. 201).

De la propagación de la Commedia en su lengua original dan cuenta dos ilustres ejemplos. En Inglaterra, Geoffrey Chauser ${ }^{23}$ que en los Cuentos de Canterbury — setenta años después de la muerte de Dante- hace narrar a uno de sus personajes la historia del conde Ugolino, y agrega que, para los que quieran conocer más, lean a Dante el gran poeta de Italia. En Francia, la famosa escritora Christine de Pizan, ${ }^{24}$ en medio de la polémica suscitada por el Roman de la Rose, aconseja leer a Dante.

\section{Las primeras publicaciones}

De la Commedia, como de todos los documentos producidos con anterioridad a la imprenta, existen varias y dispares versiones, producto de la labor de los copistas.

\footnotetext{
${ }^{20}$ Guido Novello da Polenta era poeta y sobrino de Francesca de Rimini, protagonista del canto $\checkmark$ del Infierno.

${ }^{21}$ Véase, Carta XIII al Can Grande de la Scala de Verona, en Obras completas de Dante Alighieri, 1994, pp. 812-821.

22 Véase, E. de Bruyne, 1960.

23 1343-1400. V. "Ugolino, conde de Pisa" en "El cuento del monje" en que se lee: "el que desee una versión más extensa del relato debe leer al gran poeta de Italia, Dante, pues lo describe desde el principio al fin sin omitir palabra".

${ }^{24}$ Célebre escritora y poeta veneciana (1364-1430 cir.) afincada en Francia.
} 
La primera edición impresa -editio princeps de la Commedia- data de 1472 habría sido realizada por el tipógrafo alemán Johannes Numeister, ${ }^{25}$ uno de los primeros impresores de Italia, y Evangelista Mei ${ }^{26}$ que la habría financiado. En el mismo año aparecerían otras dos ediciones: una en Jesi ${ }^{27}$ o en Venecia —el lugar es dudoso-, por los grabadores de Federigo de 'Conti de Verona; y otra en Mantua, de los impresores alemanes Georg y Paul Butzbach, editado por el humanista Colombino Veronese. La edición de 1555 y es la primera que incluyó la palabra "divina".

Muchas versiones de esta obra se sucedieron a lo largo de los siglos. Entre las más notables se cuenta la del humanista Giorgio Petracchi a quien se debe la edición crítica basada en un manuscrito anterior al utilizado por Boccaccio, que fuera publicada en cuatro volúmenes entre los años 1966 y 1967, como parte de la edición Nacional de las Obras de Dante, propuesta por la Società Dantesca Italiana. ${ }^{28}$

\section{Boccaccio descubridor de Dante}

Biografía de Dante y divulgación de la Commedia

Giovanni Boccaccio vio en la Commedia lo que aún permanecía oculto y lo desveló. ¡Cuánto debe a Boccaccio el magno poema del Alighieri! Fue él quien la apodó 'Divina'. Y también rescató la figura del autor escribiendo su semblanza en el Trattatello in laude di Dante. ${ }^{29}$ Boccaccio compuso la parte central del mismo entre 1351 y 1355, y lo reelaboró por tres veces, publicándolo en 1360 y 1365. La biografía de Dante compuesta por Boccaccio es la primera en sentido moderno, pues el autor se empeñó en investigar toda información al respecto del poeta entrevistando a personas que lo habían conocido en vida. Allí Bocaccio, aprovecha la circunstancia para exponer su doctrina acerca de la

\footnotetext{
25 Impresor natural de Maguncia, y probable discípulo de Gutemberg, establecido en Foligno (Perugia).

${ }^{26}$ También conocido como Evangelista Angelini de Trevi, Evangelista da Foligno o Emiliano Orfini.

${ }^{27}$ Antigua ciudad de Ancona, en las Marcas.

${ }^{28}$ Sociedad sin fines de lucro, creada en 1888, para mantener viva la memoria del poeta entre cuyos miembros fundadores se encontraba G. Carducci.

${ }^{29}$ Con el título de Vita di Dante, se publicó como prólogo a la edición príncipe de la Divina Commedia, impresa en 1477 por el Vindalino da Spira, el tipógrafo maguntino afincado en Venecia, junto con su hermano Giovanni.
} 


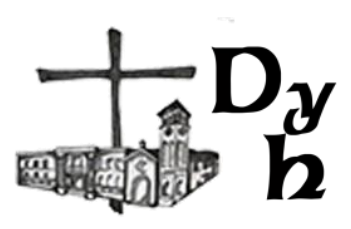

significación de la actividad poética como el único medio humano para hallar la verdad moral y teológica, de modo que éste, para cumplir su misión como intelectual, debe centrarse en ella, rehuyendo distracciones como la política y aun el matrimonio. A la vez que rechaza la importancia de la literatura inspirada en la figura femenina, disminuyendo de este modo el rol y la figura de Beatriz.

También fue Boccaccio gran divulgador de la poesía de Dante mediante el recitado de los cantos de la Commedia. Convocado por la comuna florentina, inauguró la ceremonia de la Lectura Dantis, en auge hasta nuestros días. ${ }^{30} \mathrm{El}$ acto se llevó a cabo en la Abadía (en la actual capilla Pandolfini, en donde por entonces se alzaba la iglesia de san Esteban Protomártir) y se convirtió en un resonante acontecimiento. Aquellos serían los últimos años de la vida de Boccaccio quien, por razones de salud, sólo llegó a declamar los XVII primeros cantos del Infierno.

\section{El aporte de los hijos de Dante para el conocimiento de la Comedia}

Los hijos de Dante, Jacopo y Pietro, quienes lo habían acompañado en el exilio, primero en Verona y luego en Ravena, fueron testigos de la elaboración de la magna obra.

Jacopo, ${ }^{31}$ preocupado por dar a conocer la obra paterna, compuso Chiose all'Inferno di Dante, en lengua vulgar, el primero comentario escrito al año siguiente de la muerte de Dante, y un epítome en tercetos resumiedo el tema de la Commedia. Dicho texto acompañó a la primera copia, destinata a Guido da Polenta a quien se dirije así: $O$ voi, che s(i)ete del verace lume... ${ }^{32}$

\footnotetext{
30 Nombre que incluye tanto la declamación como la exégesis. Entre los recitadores más famosos de la Commedia se cuenta Vittorio Gassman. Últimamente la posta fue tomada por Roberto Benigni con sus ciclos Tutto Dante, precedidos por un amplio comentario, ofrecidos primero en la plaza de Santa Croce, de Florencia, grabados y retransmitidos por la Radio televisión italiana (RAl), y luego en diversos países europeos y americanos.

31 Tercer hijo de Dante que le siguió en el exilio, hacia 1315. Volvió a Florencia 1325, para solucionar la situación económica familiar, logrando, en 1343, recuperar los bienes paternos confiscados. El 9 de octubre de 1326 recibió las órdenes menores con vistas a una canonjía en Verona. Se supone que falleció en Florencia en 1348, a causa de la peste negra.

32 También fue autor del Dottrinale, constituido por sesenta capítulos rimados y divididos en dos secciones referidas al orden fisico y al orden moral, en los que trata de astrología, de la fe y la virtud de la Iglesia y del Imperio, de la familia, de las bellezas humanas, el libre arbitrio, trabajo inspirado en los autores antiguos.
} 
De Pietro $^{33}$ se sabe que era también poeta, autor de rimas y canciones dentro de la estética del stil nuovo. Su labor exegética respecto de la obra paterna está contenida en: Petri Alighieri super Dantis ipsius genitoris Comoediam commentarium, redactado después de 1347 y conservado en veinte códices, mediante el cual, esclareció los puntos oscuros, los significados alegóricos, filosóficos y poéticos de la Commedia, explicando que Dante quería competir con los antiguos, y al imitarlos tenía la dignidad de un poeta clásico. Este trabajo fue considerado el más valioso producto de la vieja exégesis dedicada a esta magna obra.

Después de la muerte de Dante, Pietro pudo volver a Florencia para conocer la situación económica familar. El año siguiente decidió estudiar derecho en Boloña con la ayuda económica de Cangrande della Scala, ${ }^{34}$ el amigo y protector del poeta. En Boloña se doctoró, y también conoció a Petrarca, de quien fue amigo. No queriendo aprovechar la amnistía para los que habían cometodo delitos políticos, decidió no retornar a Florecia y establecerse en Verona definitivamente en 1331. Allí será nombrado primero delegado del Podestà y luego juez.

\section{Dante en la lengua y la literatura italiana}

\section{El origen de las lenguas vernáculas}

En el libro I del Convivio Dante se refería a lengua hablada y anticipaba el propósito de ocuparse más detenidamente del tema. Así compone el ensayo De vulgari eloquentia (Sobre la lengua vulgar) ${ }^{35}$ cuyos dos primeros libros habría planeado con anterioridad al destierro. Estos tratados a cerca del habla vernácula afrontan la cuestión del origen de las lenguas y su diversidad. Respecto del origen, Dante defiende la que posteriormente será llamada "teoría

\footnotetext{
33 Pietro Alighieri (Firenze, 1300-Treviso, 1364), primero o segundogénito del poeta, fue un juez y crítico literario de brillante carrera quien, finalmente, compró vastos terrenos con viñedos en los alrededores de Verona, residencia de los miembros de la familia Alighieri hasta la actualidad. 34 Se trata de Can Francesco della Scala (1291-1329), señor de Verona entre 1308 y 1329, a quien Dante escribe una famosa carta anunciándole el contenido de la Comedia.

${ }^{35}$ Inicialmente constaría de cuatro libros, aunque Dante desechó la idea después de redactar el segundo.
} 
de la monogénesis", 36 opinando que, en un principio se hubiera hablado una única lengua y tras la confusión de la misma consignada en el texto bíblico de la construcción de la torre de Babel, los hombres se hubieran dispersado por el mundo en todas las direcciones.

En tiempos remotos, la familia humana, supone Dante, se movió de Oriente a Occidente, ubicándose unos en el norte, otros en el sur, y los demás al este, extendiéndose por algunos territorios europeos y asiáticos y trayendo "un idioma de tres ramas". ${ }^{37}$ De aquel tronco procederían las lenguas vulgares.

Dante distinguía varias regiones lingüísticas: la del norte del Danubio, la del este, con los eslavos, y la tercera al sur que, a su vez, se dividiría en tres según sea el afirmativo: oc, oil, o sí, _entre los cuales se cuentan los hispanos, francos e italianos-, derivadas de una única matriz. ${ }^{38}$

Posteriormente, a causa del transcurrir temporal y las distancias geográficas, cada lengua sufriría diversos cambios.

Dante traza el mapa lingüístico italiano según cada región. Es un reconocimiento de la natural evolución las lenguas vernáculas habladas, pues sólo permanecen inmutables los idiomas escritos que ya no se hablan. En cambio, aquellos usados en la oralidad sufren grandes mutaciones, tanto como para no poder ser entendidos por las generaciones temporalmente distantes. Esto explica por qué no comprendemos fácilmente el idioma de nuestros antepasados y menos aún el de nuestros vecinos territoriales.

La lengua de Dante convertida en base de la unidad cultural y política de Italia

En De vulgari eloquentia y en el Convivio, obras de madurez, Dante había defendido el uso del lenguaje hablado, para la composición poética. ${ }^{39}$ Aquella lengua aprendida de modo natural escuchando a la madre o la nodriza contrastaba con el latín y el griego, asimilados dificultosamente. Por lo cual,

\footnotetext{
36 Doctrina discutida cuya primera formulación científica se debe al lingüista italiano Alfredo Trombetti (1866-1929) en L'Unità d'origine del linguaggio, de 1905.

37 "Pero ya sea como forasteros que llegaban por primera vez, ya sea que volvieran a Europa como antiguos indígenas" (Sobre la lengua vulgar, ed. cit., VIII, 2, p. 752).

${ }^{38}$ Zona meridional a partir de Génova; al oriente con la zona adriática y Sicilia, Italia; al norte comprendería la zona de Provenza.

${ }^{39}$ Los poetas del stil nuovo la usaban.
} 
prefirió la lengua romance o vulgar hablada por los florentinos de su tiempo, al que contribuyo a enriquecer, y no el latín, idioma conocido y utilizado solamente por los cultos. ${ }^{40}$

La riqueza y elegancia de la lengua usada por Dante - ya subrayada por diversos tratadistas del Renacimiento-, volvería a sensibilizar a los patriotas del Risorgimento, ${ }^{41}$ cuando se replanteó de modo apremiante la cuestión lingüística, ya que la unificación política italiana que se preparaba requería del uso universal de un único idioma. Así, actores de aquel movimiento como Alessandro Manzoni ${ }^{42}$ —el literato italiano más notable del siglo XIX - y el activista Giuseppe Mazzini ${ }^{43}$ volvieron los ojos hacia Dante.

En 1827, Manzoni se había trasladado a Toscana para embeberse en la lengua hablada florentina, consecuentemente la adopta para la edición de 1840 de su famosa novela I promessi sposi (Los novios). Para Mazzini, Dante era quien había profetizado, ya en el siglo XIV, la unidad de Italia y cuyas obras reflejaban un amor patrio que trascendían los límites de Florencia, abarcando todo il Bel Paese $^{44}$ en donde resuena el sí. Dante representaba para Mazzini, al exilado que había pagado con el destierro su lucha permanente y heroica contra todo tipo de injusticia y formas de vasallaje.

La lengua usada por el Sumo Poeta sería un principio de unidad capaz de sobreponerse a la diversidad de los regionalismos. Resultaba indiscutible: la Italia unificada hablaría la lengua de Dante.

40 Con De vulgari eloquentia, Dante inaugura la larga controversia sostenida en el ámbito literario, conocida como "la cuestión de la lengua" en la que se alistaron intelectuales de nota hasta el siglo XIX.

${ }^{41}$ Movimiento cultural, político y social que promovió la unificación de Italia que hunde sus raíces en el Romanticismo con la mirada puesta en el ideal de la romanidad.

42 (1785-1873) redactor también de un informe para el ministro de Educación recomendando el uso de esa lengua, y de un vocabulario de la misma.

${ }^{43}$ Político, filósofo, periodista genovés (1805-1872).

${ }^{44}$ Expresión poética usada por Dante (Inf. XXXIII, 80) y luego por Petrarca (Canzoniere, CXL VI. 13-14) que se convertiría en sinónimo de Italia. 


\section{Los Papas que se ocuparon de Dante}

\section{Benedicto XV}

Benedicto $\mathrm{XV},{ }^{45}$ el pontífice que debió atravesar la primera guerra mundial sin poder evitarla ni contenerla, inaugura la lista de los Papas que escribieron sendos documentos para celebrar una efeméride de Dante, nada menos que el VI Centenario de su muerte.

Este Papa ya se había interesado en el poeta mediante la carta Nobis, ad catholicam, fechada el 28 de octubre de 1914, y dirigida al arzobispo de Ravena, en vistas a las próximas conmemoraciones. En la misiva, Benedicto XV agradecía al prelado sus labores para honrar a Dante, recordando que sus antecesores siempre habían enaltecido las artes y las letras y alabado a aquellos que se distinguieran especialmente en esos campos. Y más aún tratándose de Alighieri, "comparable con el antiguo Homero". Es así como aquel papa impulsa y apoya económicamente la iniciativa de restauración de la Iglesia de San Pedro Mayor, conocida popularmente como de San Francisco, en donde se había efectuado el funeral del insigne poeta y en cuyo cementerio fue sepultado:

para que le sea restituida la antigua dignidad exterior y el esplendor del arte originario, se torne más majestuosa y más digna de las cenizas de un hombre tan grande (Benedicto XV, 1914).

En la proximidad de dicho centenario mucho se estaba escribiendo. El filósofo Giovanni Gentile, por ejemplo, era autor de un estudio sobre la poesía de Dante, centrándose en el concepto de nacionalidad.

Con Dante, Italia comienza a afirmarse idealmente; con su Poema la filosofía italiana (Studi su Dante, pp. 19-20).

Y remata:

[...] en todas las épocas, Dante ha sido considerado "padre espiritual de la nación", y su poesía es su filosofía.

${ }^{45}$ El papa Benedicto XV (1854-1922), reinó entre 1914 y 1922. 
Era patente el aprovechamiento que se hacía del prestigio literario del florentino. Benedicto XV trata, entonces, de rescatar la figura de Dante.

Nos pareció bien que instruyáis a todos en el significado de lo que hacemos, en las estrechas relaciones de Alighieri con esta Cátedra de Pedro, en la gran necesidad que hay de unir con la fe católica las alabanzas tributadas a tan gran nombre (1914).

Hay una poderosa razón para celebrar solemnemente su aniversario, especifica el papa:

[...] el hecho de que el Alighieri es nuestro. De hecho, el poeta florentino, como todos saben, unió el amor por la naturaleza al amor por la religión y conformó su mente con los preceptos derivados de la fe católica y alimentó su alma con los más puros y elevados sentimientos de humanidad y justicia (1914).

Recomienda que el acontecimiento sea conmemorado con gran asistencia de público.

Y agrega:

¿Quién podrá negar, en efecto, que nuestro Dante haya alimentado e intensificado la llama del ingenio y la virtud poética obteniendo inspiración de la fe católica, a tal punto que cantó en un poema casi divino los misterios sublimes de la religión? (1914).

Las circunstancias que rodeaban la aparición de la encíclica In praeclara summorum, del 30 de abril de 1921, eran complejas: por un lado, la hostilidad hacía la iglesia, por otro, las voces condenatorias respecto de la ortodoxia de Dante, de su postura respecto de Bonifacio VIII y de la división de poderes respecto del estado y la iglesia que lo hacían sospechoso de un agresivo y recalcitrante laicismo.

En esta encíclica, Benedicto XV, con un fino uso del método escolástico, ahuyenta toda duda y recelo respecto de la ortodoxia del gran poeta, reconociéndolo como hijo dilecto de la Iglesia.

El papa comienza su encíclica afirmando: 
Entre el grupo de hombres eminentes que han dado esplendor y gloria a la fe católica — que se han distinguido en todos los campos, y, en particular, en el de las letras y las artes, de modo que por las inmortales obras de su ingenio han merecido alabanza, tanto de la sociedad civil como de la Iglesia-, ocupa un lugar privilegiado Dante Alighieri, de cuya muerte se celebrará en breve el sexto centenario. Nunca, tal vez, como hoy la singular grandeza de este hombre fue puesta a tal luz, mientras no sólo Italia, con razón orgullosa de haberlo dado a luz, sino todas las naciones civilizadas, a través de comités especiales de eruditos, se preparan para solemnizar su memoria, así que este genio sublime, que es el orgullo y la dignidad de la humanidad, sea honrado por el mundo entero (Benedicto XV, 1921, 1).

Y dirigiéndose a los estudiantes cristianos, recomienda amar y valorar al poeta que califica con certeza de "cantor y heraldo elocuente del pensamiento cristiano".

En el momento que las naciones del mundo se aprestaban a homenajearle, proclama:

Nosotros no sólo no podemos estar ausentes en el magnífico coro, sino más bien debemos presidirlo, pues compete sobre todo a la Iglesia, su madre, Ilamarlo su Alighieri (1921, Introd.).

El papa Benedicto XV responde a cada uno de los malos entendidos y acusaciones contra Dante comenzando por resaltar la formación escolástica de Dante bajo los auspicios de Santo Tomás y asegura que todo lo que relata en la Commedia tiene por objeto presentar los dogmas católicos.

Nacido en una época en que florecían los estudios filosóficos y teológicos, Dante en medio de las diversas corrientes de pensamiento se hizo discípulo del príncipe de la Escolástica Tomás de Aquino y de su mente angélica tomó casi todos sus conocimientos filosóficos y teológicos en tanto que no descuidaba ninguna rama del saber humano y bebía en las fuentes de la Sagrada Escritura y de los Padres (1921, p. 2, §5). 
Refiriéndose a su astronomía, justifica que, si bien aquellos conocimientos, con el tiempo, mostraron ser errados, no constituyen la sustancia del mensaje, a saber:

[...] sigue siendo cierto el que esta estructura universal, sea cual sea el orden que rige en sus partes, está gobernada por la misma voluntad que la ha creado, que es la de Dios Omnipotente, que mueve todas las cosas, cualesquiera ellas sean, y que en todas partes resplandece con su gloria. Aunque esta tierra que los hombres habitamos no puede decirse, como se dijo, que era como el centro del universo; sin embargo es cierto que ella fue el lugar de la edénica vida de nuestros primeros padres y que fue después testigo tanto de nuestra tristísima caíd con que ellos perdieron aquel estado, como de la restitución de la salud eterna de los hombres por la sangre de Jesucristo. En consecuencia explicó los tres estados de las almas, que en su mente había concebido, de un modo tal, que para describir antes del día postrero del juicio divino, ya la condenación de los réprobos, ya la purificación de las piadosas almas del purgatorio, ya la felicidad de los bienaventurados, parecía auxiliarse con la luminosa claridad que dan las profundas enseñanzas de la fe $(1921$, p. 2 , § 8).

Recalca, también, la vigencia de la enseñanza de la obra de Dante, con su afirmación del valor de la Sagrada escritura, el aprecio por los escritos de san Agustín y de los demás doctores.

Respecto de la relación de Dante con los papas, Benedicto XV rescata el reconocimiento que el poeta hace de la autoridad apostólica, y propone considerar las causas profundas de sus disidencias respecto de los pontífices de su tiempo. Benedicto XV distingue en las palabras y actos de Dante dos hechos: los rumores que rodeaban la situación, y que también había muchas cosas condenables en el ámbito religioso.

Por otra parte, ya que "es preciso"- tal es la flaqueza de los mortales- "que hasta los corazones religiosos se manchen con el polvo del mundo", ¿quién negará que muchas cosas había en aquel tiempo que no podían aprobarse en hombres consagrados; todo lo cual llenó de aflicción y malestar su ánimo enteramente consagrado a la Iglesia, y hasta hizo que varones de gran santidad de vida dejaran sentir graves quejas? (1921, p. 4). 


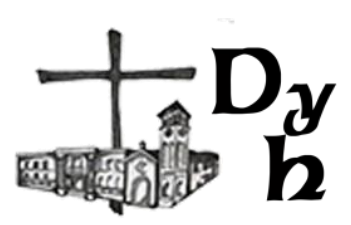

Sin embargo, cabe afirmar en honor de Dante que:

lo que justa o injustamente reprendió y vituperó en los clérigos, de ningún modo quiso extenderlo y aplicarlo al honor debido a la Iglesia, o a la veneración debida a las llaves de Pedro (1921, p. 4).

En cuestiones políticas y temporales Dante defendió sus propias opiniones, sin por ello ofender o menoscabar a la religión de la que nunca renegó.

El valor de la Commedia de Dante, pues, hay que buscarlo en otra cosa: por estar inspirada en los principios de la religión y que en ella —asegura— "se encuentra oculto, puede decirse, un tesoro de la doctrina católica, es decir, la savia de la filosofía y teología cristianas, y el conjunto de las leyes divinas para el gobierno y administración de los asuntos públicos." (p. 4). Dante no oponía la organización secular de los estados a la fe. Pero, además, conviene recordar como "la variedad de las imágenes, el colorido, y la grandiosidad de los pensamientos y lenguaje, atrae y excita al amor de la sabiduría cristiana" y como él mismo "confesó abiertamente haber compuesto el efecto sobre los espíritus de la belleza de su obra, que aun hubo logrado en algunos la aproximación a la verdad y a la fe [...] Y este poema con la intención de facilitar a todos un poco de sustento vital" (p. 4).

Más aún, el Papa añade:

[...]sabemos que algunos $-Y$ aún de reciente memoria, que estaban alejados de Cristo, sin ser contrarios a él- al dedicarse principalmente a la lectura y estudio del poeta, con el auxilio de Dios, se interesaron primero en la verdad de la fe católica y por ese camino se acogieron gustosísimos al seno de la Iglesia (1921, p. 5).

Por lo cual cabe reconocer sin mezquindades que, a pesar la distancia temporal, su pensamiento y obra sigue siendo actual, esto es capaz de fecundar el hoy. Una misma vestidura reviste a "la verdad venida a nosotros desde el cielo, por la cual somos elevados a lo sublime" (p. 5). 
Ser poeta cristiano significa, para esta Papa, abrirse a un conocimiento acabado de la verdad puesto que resulta falseo que "la consagración de la mente y del corazón a Dios corte las alas del ingenio, mientras, por el contrario, lo espolea y lo eleva" (p. 5).

Y a continuación lamenta que, aunque su lectura se ofrezca a los jóvenes, se la tergiversa al presentarse el magno poema como una construcción fabulosa puramente literaria en el contexto de una educación que reniega de toda religiosidad "como si el hombre no tuviera ninguna noticia de su Dios, ni de aquellas máximas verdades que están por encima de la naturaleza" (p. 5).

El propósito del poeta era, en fin, como él mismo declara:

"elevar a los seres vivientes de esta vida por sobre el estado de miseria", es decir, del pecado, "y llevarlos al estado de felicidad que es el de la gracia divina (1921, p. 5).

\section{San Pablo VI y Dante}

Era conocido el fervor de Giovanni Battista Montini por la Divina Comedia. Se sabe que con frecuencia se hacía leer por su secretario privado algún canto del inmortal poema. ${ }^{46}$

El año1965 se festejaba el séptimo centenario del nacimiento de Dante y el entonces papa Pablo VI participó activamente en los homenajes. Donó una Cruz dorada para coronar el templete construido en Ravena el 19 de septiembre, envió a Florencia una corona dorada de laureles a fin de ser colocada en el Baptisterio de San Juan, donde Dante fuera bautizado ${ }^{47}$ y, con motivo de la finalización del Concilio Ecuménico Vaticano II, regaló a los padre conciliares una edición artística de la Divina Comedia.

Mediante una Carta Apostólica en forma de Motu proprio, fechada el 7 de diciembre de 1965 —día previo al cierre del Concilio Vaticano II-, el papa Montini publica un refinado texto dedicado al recogiendo los diversos aspectos de la obra poético-teológica de Dante: Alttisimi cantus

Refrendando lo expresado por Benedicto XV asevera:

\footnotetext{
${ }^{46}$ Véase: el artículo de Gianfranco Ravassi, publicado en Avvenire, el 9 de diciembre de 2015.

${ }^{47} \mathrm{Tal}$ como lo hace saber en carta al secretario de estado Cardenal Cicognani del $5 / 11 / 1965$.
} 
Si alguno quisiera preguntarse por qué la Iglesia católica, por deseo de su Cabeza visible, se preocupa de cultivar la memoria y celebrar la gloria del poeta florentino, fácil es nuestra respuesta: porque, por un derecho particular, Dante es nuestro. Nuestro, es decir de la fe católica, porque todo inspira amor a Cristo; nuestro porque amó mucho a la Iglesia, de la que cantó sus glorias; y nuestro porque reconoció y veneró en el Romano Pontífice al Vicario de Cristo (Pablo VI, 1965).

Y a continuación detalla:

En el majestuoso coro de los poetas cristianos, donde se distinguen Prudencio, San Efrén de Siria, San Gregorio Nacianceno, San Ambrosio obispo de Milán, San Paulino de Nola, Venancio Fortunato, San Andrés de Creta, Romano el Méloda, Adán de San Víctor, San Juan de la Cruz y otros — que sería muy largo enumerar - la cítara dorada, la armoniosa lira de Dante resuena con toques admirables, soberana por la grandeza de los temas tratados, por la pureza de la inspiración, por el vigor combinado con una exquisita elegancia (1965).

Pablo VI califica a Dante como "el poeta de los teólogos y el teólogo de entre los poetas" y anuncia que antes que una nueva estatua del gran poeta:

[...] hemos decidido erigir, de acuerdo con las autoridades académicas competentes, una cátedra de Estudios Dante dentro esa sede de disciplinas superiores, al que tanto interés dedicó nuestro venerable predecesor Pío XI, y después de él los sucesivos Romanos Pontífices. a nosotros, que siempre, y especialmente durante el período de nuestro ministerio en Milán, lo hemos tenido en gran honor y cariño; nos referimos a la Universidad Católica del Sagrado Corazón de Milán. Por lo tanto, establecemos Motu proprio, por iniciativa nuestra, ique debe tener su cátedra dantesca!

Aquel Papa sueña con que:

Surgirán alumnos -esta esperanza nos ilumina - inteligentes y devotos, capaces de convertirse ellos mismos en profesores de Filología de Dante, de los que todos los tesoros del Poeta pueden derivarse del estudio y resurgimiento en la cultura de la nueva generación. 


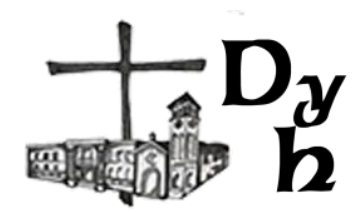

DIOS Y EL HOMBRE

San Juan Pablo II y Benedicto XVI tampoco fueron indiferentes a la memoria del Alighieri

Estos grandes pontífices, aunque no tuvieron la oportunidad de celebrar un aniversario destacado, no permanecieron al margen de la vigente presencia del "Sumo Poeta", recordándolo y comentándolo en diversas ocasiones.

San Juan Pablo II lo cita repetidas veces, tanto para recordar su genio como para reflexionar acerca de su mensaje.

Me permito recordar las palabras pronunciadas al finalizar de Lectura Dantis celebrada en el Palacio Apostólico de Castelgandolfo, el 31 de agosto de 1997, y realizada por el profesor Vittorio Sermonti, con la presencia del vicepresidente del gobierno italiano, el arzobispo de Ravena, y el presidente de la asociación "Dante Alighieri".

Esta tarde, con la lectura del último canto del "Paraíso", hemos sido invitados a convertirnos también nosotros en peregrinos del espíritu y a dejarnos guiar por la sublime poesía de Dante y contemplar "el Amor que mueve al sol y a las demás estrellas", fin supremo de la historia y de toda vida humana. En efecto, el sumo Poeta indica en estos versos la meta definitiva de la existencia, donde las pasiones se aplacan y donde el hombre descubre su límite y su singular vocación de llamado a la contemplación del misterio divino (Juan Pablo II, 1997, 1).

Y añade:

En el grandioso escenario que propone al hombre en busca de salvación, el Poeta reserva un lugar central a María, "humilde y alta, más que cualquier otra criatura", imagen familiar y sublime de mujer que ilumina la parábola de la última ascensión, después de haber sostenido el arduo camino del viajero. ¡Qué visión más consoladora!

Casi siete siglos después, el arte de Dante, evocando sublimes emociones y certezas supremas, es aún capaz de in fundir valor y esperanza, orientando la difícil búsqueda existencial del hombre de nuestro tiempo, hacia la Verdad que no tiene ocaso $(1997,2)$.

En el discurso de la inauguración de la muestra Dante en el Vaticano (30 de mayo de 1985), Juan Pablo II declara: 
En tiempos de una civilización visual que confía sus mensajes a la velocidad de comunicación con los medios masivos de comunicación, la poesía puede parecer lejana de la realidad. Sin embargo, el mundo del Dante medieval pudo pasar a través de vosotros, en vuestra conciencia; lo habéis vivido espiritualmente para poder donarlo, una vez más, a través del valor de las formas artísticas. [...]. Ustedes, queridos artistas, ciertamente han escuchado los llamados de una historia perenne que resurge hoy con diferentes nombres, y por eso se han acercado a Dante, viendo nuestro mundo actual y nuestras esperanzas reflejadas en él. Dante luchó por la justicia, no la obtuvo de los hombres, se la pidió a Dios; su fe lo apoyó en su viaje terrenal, a pesar del exilio y las condenas (Juan Pablo II, 1985, 1).

Y, a continuación, el Papa ofrece una preciada reflexión:

Hay una valiosa indicación que forma parte de la ascesis cristiana y que en italiano se expresa en expresa en con un verbo muy eficaz: "transhumanizar". Este fue el esfuerzo supremo de Dante: asegurar que el peso de lo humano no destruyese lo divino presente en nosotros, ni la grandeza de lo divino anulase el valor de lo humano $(1985,3)$.

Con ese término Juan Pablo II enriquece la comprensión de los versos dantescos.

Por eso el Poeta leyó acertadamente su historia personal y la de toda la humanidad en clave teológica; por eso espiritualizó el sistema planetario, vio los cielos como narradores privilegiados de la gloria de Dios, inundó de luz los acantilados del Purgatorio y los cielos del Paraíso. La luz, en particular: todo el Medioevo habló de la luz, buscó la luz en el esplendor de los mosaicos por la vibración de las teselas musivas, quiso una luz diferente en las iglesias mediante las famosas vidrieras historiadas $(1985,3)$.

De los escritos del santo padre Benedicto XVI sobre Dante sobresale el Discurso del lunes 23 de enero de 2006 a los participantes en un congreso internacional organizado por el consejo pontificio "Cor Unum". En el mismo, el Papa relaciona su encíclica Deus caritas est (25 de diciembre de 2005) con la poesía y el pensamiento de aquél. 


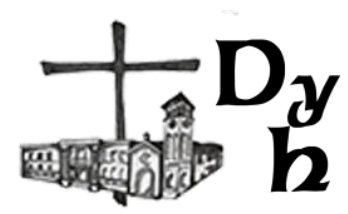

DIOS Y EL HOMBRE

La excursión cósmica, en la que Dante en su Divina Comedia quiere implicar al lector, termina ante la Luz perenne que es Dios mismo, ante la Luz que es a la vez "el amor que mueve el sol y las demás estrellas" (Paraíso, XXXIII, v. 145) (Benedicto XVI, 2006, 1).

Tras enfatizar la devaluación que actualmente sufre la palabra 'amor', el papa confiesa:

Mi intención era expresar, para nuestro tiempo y para nuestra existencia, algo de lo que Dante, en su visión, sintetizó de modo audaz. Narra una "visión" que se "reforzaba" mientras él la contemplaba y que lo transformaba interiormente (cf. Paraíso, XXXIII, vv. 112-114). Se trata precisamente de que la fe se convierta en una visión-comprensión que nos transforme. Yo deseaba destacar la centralidad de la fe en Dios, en el Dios que asumió un rostro humano y un corazón humano. La fe no es una teoría que se puede seguir o abandonar. Es algo muy concreto: es el criterio que decide nuestro estilo de vida $(2006,4)$.

Para luego aclarar que luz y amor son una única realidad: "Son la fuerza creadora primordial que mueve el universo". Y si bien el poeta lo hubo tomado de Aristóteles "la mirada de Dante vislumbra algo totalmente nuevo e inimaginable para el filósofo griego".

No sólo que la Luz eterna se presenta en tres círculos a los que él se dirige con los densos versos que conocemos: "Oh Luz eterna, que en ti solamente resides, que sola te comprendes, y que siendo por ti a la vez inteligente y entendida, te amas y te complaces en ti misma" (Paraíso, XXXIII, vv. 124-126) $(2006,1)$.

Y también, como Romano Guardini, ${ }^{48}$ destaca lo notable de la aparición de la imagen de Cristo en la Trinidad.

En realidad, más conmovedora aún que esta revelación de Dios como círculo trinitario de conocimiento y amor es la percepción de un rostro humano, el rostro de Jesucristo, que se le presenta a Dante en el círculo central de la Luz.

${ }^{48}$ Véase, El ángel en la Divina comedia del Dante, trad. de A. L. Bixio, Buenos Aires, Emecé, nota 1, p. 70. 
Dios, Luz infinita, cuyo misterio inconmensurable el filósofo griego había intuido, este Dios tiene un rostro humano y —podemos añadir- un corazón humano $(2006,2)$.

\section{El papa Benedicto XVI señala:}

Esta visión de Dante muestra, por una parte, la continuidad entre la fe cristiana en Dios y la búsqueda realizada por la razón y por el mundo de las religiones; pero, al mismo tiempo, destaca también la novedad que supera toda búsqueda humana, la novedad que sólo Dios mismo podía revelarnos: la novedad de un amor que ha impulsado a Dios a asumir un rostro humano, más aún, a asumir carne y sangre, el ser humano entero. El eros de Dios no es sólo una fuerza cósmica primordial; es amor, que ha creado al hombre y se inclina hacia él, como se inclinó el buen samaritano hacia el hombre herido y despojado, tendido al borde del camino que bajaba de Jerusalén a Jericó $(2006,2)$.

\section{El papa Francisco y su carta apostólica Candor lucis aeternae}

No es la primera vez que el Papa Francisco se ocupa de la figura de Dante. En la encíclica Lumen fidei, de 2013, el papa Francisco, refiriéndose a la fe que asimila a la luz, decía: "la fe no habita en la oscuridad, sino que es luz en nuestras tinieblas", y citaba a Dante evocando los versos del Paraíso:

Dante, en la Divina Comedia, después de haber confesado su fe ante san Pedro, la describe como una "chispa, / que se convierte en una llama cada vez más ardiente / y centellea en mí, cual estrella en el cielo"49 $(2013,4)$.

A ello se sumó el mensaje dirigido al presidente del consejo pontificio de la cultura, Cardenal Gianfranco Ravassi, el 4 de mayo de 2015, solemne celebración del 750 aniversario del nacimiento de Dante.

El mensaje comenzaba así:

Con este mensaje quiero unirme también yo al coro de quienes consideran a Dante Alighieri un artista de altísimo valor universal, que tiene aún mucho que decir y dar, a través de sus obras inmortales, a quienes están deseosos por

${ }^{49}$ Paraíso XXIV, 145-147. 


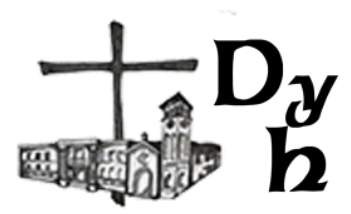

DIOS Y EL HOMBRE

recorrer la senda del conocimiento, del auténtico descubrimiento de sí, del mundo, del sentido profundo y trascendente de la existencia (Francisco, 2015).

Y a continuación mencionaba los documentos suscriptos pos sus ilustres predecesores: Benedicto XV, Pablo VI, Juan Pablo II y Benedicto XVI.

En la carta apostólica Candor lucis aeternae, firmada el 25 de marzo de 2021, el papa Francisco vuelve a recoger la tradición de los pontífices romanos de recordar al poeta florentino.

[...] en esta circunstancia no puede faltar la voz de la Iglesia que se asocia a la unánime conmemoración del hombre y del poeta Dante Alighieri. Mucho mejor que tantos otros, él supo expresar, con la belleza de la poesía, la profundidad del misterio de Dios y del amor [...]. Con esta Carta apostólica deseo unir mi voz a las de mis Predecesores que han honrado y celebrado al poeta, particularmente en los aniversarios de su nacimiento o de su muerte, para proponerlo nuevamente a la atención de la Iglesia, a la universalidad de los fieles, a los estudiosos de literatura, a los teólogos y a los artistas. Recordaré brevemente estas intervenciones considerando principalmente a los Pontífices del último siglo y sus documentos de mayor relieve (Francisco, 2021, Introd.).

El papa Francisco comienza su carta considerando a la vida de Dante como "paradigma de la condición humana", subrayando su "actualidad y perennidad" no tan solo para los creyentes, sino para la entera humanidad. De allí en más, mediante una fina biografía, el texto rememora los aspectos esenciales de la vida de Dante: la pertenencia a su ciudad natal, la carrera política, el doloroso exilio y el nunca apagado deseo de retorno.

Dante, reflexionando profundamente sobre su situación personal de exilio, de incertidumbre radical, de fragilidad y de constante desplazamiento, la transforma, sublimándola, en un paradigma de la condición humana, que se presenta como un camino, interior antes que exterior, que nunca se detiene hasta que no llega a la meta $(2021,2)$.

Por lo que papa Francisco expresa: 
Nos encontramos así con dos temas fundamentales de toda la obra dantesca: el punto de partida de todo itinerario existencial, que es el deseo, ínsito en el alma humana, y el punto de llegada, que es la felicidad, dada por la visión del Amor que es Dios $(2021,2)$.

Pero Dante, a pesar de todos sus fracasos no cedió al desaliento ni ante los atropellos:

nunca se resignó, no sucumbió, no aceptó que se suprimiera el anhelo de plenitud y de felicidad presente en su corazón, ni mucho menos se resignó a ceder a la injusticia, a la hipocresía, a la arrogancia del poder y al egoísmo que convierte a nuestro mundo en «la pequeña tierra que nos hace tan feroces» (Par. XXII, 151) (2021, 2).

Es por ello que Francisco concibe a Dante como "poeta de la esperanza", pues:

[...] releyendo la propia vida sobre todo a la luz de la fe, descubrió también la vocación y la misión que le habían sido confiadas, y mediante las cuales, paradójicamente, de hombre aparentemente fracasado y decepcionado, pecador y desalentado, se transformó en profeta de esperanza $(2021,3)$.

Francisco interpreta a través de la lectura de Carta a Cangrande della Scala cuál es la verdadera finalidad de la obra de Dante:

[...] apartar a los mortales, mientras viven aquí abajo, del estado de miseria y llevarlos al estado de felicidad» (XIII, 39 [15]) [...] entendida sea como plenitud de vida en la historia que como bienaventuranza eterna en Dios $(2021,3)$.

Se trata de una misión que se ha de vivir con valentía, dice Francisco, apoyándose en los versos de

«Y tú, hijo, que, por el peso de lo mortal / aun volverás allá abajo, abre la boca / y no escondas lo que yo no escondo» (XXVII, 64-66) (2021, 3). 
Misión profética que incluye la denuncia y la crítica dirigida a los creyentes de cualquier condición dentro de la Iglesia que alejándose del espíritu de la Bienaventuranzas y la caridad la instrumentalizan y transmutan en pro de sus intereses:

[...] pues todo lo que la Iglesia guarda / pertenece a la gente que pide por Dios, / y no a los parientes o a otros más indignos» (Par. XXII, 82-84) (2021, 3).

De este modo Dante defiende la renovación de la Iglesia:

[...] por medio de las palabras de san Pedro Damián, san Benito y san Pedro, a la vez que denuncia la corrupción de algunos sectores de la Iglesia, se hace portavoz de una renovación profunda, e invoca a la Providencia para que la impulse y la haga posible:

«Pero la alta providencia, que con Escipión / defendió en Roma la gloria del mundo, / la socorrerá pronto, según pienso» (Par. XXVII, 61-63).

A continuación, Dante es presentado por Francisco como "cantor del deseo humano", del más profundo anhelo del corazón:

El poeta, partiendo de su propia condición personal, se convierte así en intérprete del deseo de todo ser humano de proseguir el camino hasta llegar a la meta final, hasta encontrar la verdad, la respuesta a los porqués de la existencia, hasta que, como ya afirmaba san Agustín, ${ }^{50}$ el corazón encuentre descanso y paz en Dios $(2021,4)$.

Se trata dice, apoyándose en El Convite, del retorno de toda cosa a regresar a su principio (IV, XII, 14-15), por lo cual el alma desea retornar a Dios, "como el peregrino que va por un camino que nunca ha recorrido, cree que toda casa que ve desde lejos es un albergue, $\mathrm{y}$, viendo que no es tal, dirige su esperanza a otra, y así de casa en casa hasta que llega al albergue", al Sumo Bien. Dante subraya: 
la necesidad profunda e interior de cambiar la propia vida para poder alcanzar la felicidad y de esta manera mostrarle el camino a quien se encuentra, como él, en una "selva oscura" y ha perdido "la recta vía". Además, resulta significativo que su guía, el gran poeta latino Virgilio, desde la primera etapa de este recorrido, le indique la meta que debe alcanzar, animándolo a que no se rinda ante el miedo y el cansancio: «Pero tú, ¿por qué vuelves a tanta pena? / ¿Por qué no subes al deleitoso monte / que es causa y principio de toda alegría?» (Inf. I, 76-78) (2021, 4).

Francisco también reconoce en Dante al "poeta de la misericordia y de la libertad humana", pues la peregrinación del retorno no es vista como ilusoria, sino como real y posible a causa, en primer lugar, de la misericordia divina y luego de libertad de la que gozamos, manifiesta por Dante en los encuentros con diversos personajes que por algún gesto piadoso o por el arrepentimiento lograron encontrar el camino de la salvación.

Dante se convierte en paladín de la dignidad de todo ser humano y de la libertad como condición fundamental tanto de las opciones de vida como de la misma fe. El destino eterno del hombre —sugiere Dante narrándonos las historias de tantos personajes, ilustres o poco conocidos- depende de sus elecciones, de su libertad. Incluso los gestos cotidianos y aparentemente insignificantes tienen un alcance que va más allá del tiempo, se proyectan en la dimensión eterna $(2021,5)$.

Pero el Poeta sabe que la libertad no es un fin en sí mismo, sino que:

es condición para ascender continuamente, y el recorrido a través de los tres reinos nos ilustra plásticamente precisamente este ascenso hasta tocar el Cielo, hasta alcanzar la plena felicidad. El «alto deseo» (Par. XXII, 61) que suscita la libertad sólo puede extinguirse cuando se llega a la meta, a la visión última y a la bienaventuranza: «Y yo, que al fin de todos los deseos / me aproximaba, puse término como debía / a la vehemencia de mi ardor» (Par. XXXIII, 46-48) (2021, $5)$.

Deseo convertido en plegaria, agrega Francisco: 
La paráfrasis del Padrenuestro que propone el poeta (cf. Purg. XI, 1-21) entrelaza el texto evangélico con la vivencia personal, con sus dificultades y sufrimientos: «Venga a nos la paz de tu reino, / porque no podemos alcanzarla por nosotros mismos si ella no viene. [...] El pan nuestro de cada día dánosle hoy, / porque sin él, en este áspero desierto, / hacia atrás camina quien más adelante se afana por ir» (7-8.13-15) $(2021,5)$.

Y plegaria que refuerza la libertad:

La libertad de quien cree en Dios como Padre misericordioso, no puede más que confiarse a Él en la oración, y esto no la perjudica en absoluto, por el contrario, la fortalece $(2021,5)$.

Sin embargo, recalca Francisco, recordando también lo expresado por Benedicto $\mathrm{XVI}$, ello no supone una reducción de lo humano, sino que contiene la existencia histórica.

En el itinerario de la Comedia, como ya señaló el Papa Benedicto XVI, el camino de la libertad y del deseo no lleva consigo, como tal vez se podría imaginar, una reducción de lo humano en su realidad concreta, no saca fuera de sí a la persona, no anula ni omite lo que ha constituido su existencia histórica (2021, $6)$.

Y, por tanto:

Sólo en la visio Dei se sacia el deseo del hombre y su fatigoso camino termina completamente: «mi mente iluminada / por un fulgor que satisfizo su deseo. / A la alta fantasía le faltaron aquí las fuerzas» (140-142) $(2021,6)$.

De lo cual Francisco deduce que "el misterio de la Encarnación [...] es el verdadero centro inspirador y el núcleo esencial de todo el poema.

En éste se realiza lo que los Padres de la Iglesia Ilamaban "divinización", el admirabile commercium, el intercambio prodigioso mediante el cual, mientras Dios entra en nuestra historia haciéndose carne, el ser humano, con su carne, puede entrar en la realidad divina, simbolizada por la rosa de los bienaventurados. La humanidad, en su realidad concreta, con los gestos y las 
palabras cotidianas, con su inteligencia y sus afectos, con el cuerpo y las emociones, es elevada a Dios, en quien encuentra la verdadera felicidad y la realización plena y última, meta de todo su camino. Dante había deseado y previsto esta meta al comienzo del Paraíso: «esto debería encender más el deseo / de ver aquella esencia en la cual se sabe / que nuestra naturaleza y la de Dios se unieron. / Allí se verá lo que creemos por fe, / sin estar demostrado, pero que se nos hace tan evidente / como los primeros axiomas que el hombre admite» (II, 40-45) (2021., 6).

El documento del papa Francisco se centra en el tema de la Anunciación.

El día en que la liturgia celebra este inefable misterio es también particularmente significativo en las vicisitudes históricas y literarias del sumo poeta Dante Alighieri, profeta de esperanza y testigo de la sed de infinito ínsita en el corazón del hombre $(2021,6)$.

Y explica a continuación:

el 25 de marzo, en efecto, comenzaba en Florencia el año según el cómputo $a b$ Incarnatione.

Dicha fecha, cercana al equinoccio de primavera y en perspectiva pascual, estaba asociada tanto a la creación del mundo como a la redención realizada por Cristo en la cruz, inicio de la nueva creación. Esta fecha, por lo tanto, a la luz del Verbo encarnado, invita a contemplar el proyecto de amor que es el núcleo mismo y la fuente inspiradora de la obra más célebre del poeta, la Divina Comedia, en cuyo último cántico san Bernardo recuerda el acontecimiento de la Encarnación con estos célebres versos: «En tu vientre se encendió el amor, / por cuyo calor, en la eterna paz / esta flor germinó» (Par. XXXIII, 7-9)[1]. Anteriormente, en el Purgatorio, Dante representaba la escena de la Anunciación esculpida en un barranco de piedra (X, 34-37.40-45).

Por lo cual subraya:

El misterio de la Encarnación, que hoy celebramos, es el verdadero centro inspirador y el núcleo esencial de todo el poema $(2021,6)$. 
No falta en la Carta papal un párrafo resaltando la intervención de las figuras femeninas en poema del Alighieri.

Al comienzo del arduo itinerario, Virgilio, el primer guía, conforta y anima a Dante para que siga adelante, porque tres mujeres interceden por él y lo guiarán: $(2021,7)$

Y éstas son:

María, la Madre de Dios, figura de la caridad; Beatriz, símbolo de la esperanza y santa Lucía, imagen de la fe $(2021,7)$.

Según el papa Francisco, María, Beatriz y Lucía aparecen como aquellas que "cantan el misterio de la encarnación".

De María, Dante, dice, propone un "hermoso tratado de Mariología"

Con acentos líricos altísimos, particularmente en la oración pronunciada por san Bernardo, sintetiza toda la reflexión teológica sobre María y su participación en el misterio de Dios: «Virgen madre, hija de tu Hijo, / la más humilde y alta de las criaturas, / término fijo de la eterna voluntad, / tú eres quien la humana naturaleza / ennobleciste, de modo que su hacedor / no desdeñó convertirse en su hechura» (Par. XXXIII, 1-6) (2021, 7).

Beatriz —símbolo de la esperanza-, asegura que "la única fuente que nos puede dar la salvación es el amor, el amor divino que transfigura el amor humano".

Luego, dirigiéndose a Beatriz, interviene Lucía: «Beatriz, alabanza de Dios verdadero, / ¿por qué no socorres a quien tanto te amó, / que se alejó por ti de la esfera vulgar?» (103-105). Dante reconoce que sólo quien es movido por el amor puede verdaderamente sostenernos en el camino y llevarnos a la salvación, a la renovación de la vida y, por consiguiente, a la felicidad. $(2021,7)$.

No olvida el papa Francisco la aparición del santo de Asís en la Commedia. En efecto, para él, Dante está en perfecta sintonía con el Poverello: 
El primero, salió del claustro junto con los suyos y anduvo entre la gente por los caminos de aldeas y ciudades, predicando al pueblo, quedándose en las casas; el segundo hizo la elección, incomprensible en esa época, de usar la lengua de todos para el gran poema del más allá, poblando su narración de personajes conocidos y menos conocidos, pero todos iguales en dignidad a los poderosos de la tierra. Los dos personajes tienen otro rasgo en común: la apertura a la belleza y al valor del mundo de las criaturas, espejo y "vestigio" de su Creador $(2021,8)$.

Y encuentra en la paráfrasis del Padrenuestro una referencia al Cántico de las criaturas:

¿Cómo no reconocer en aquel «alabado sea tu nombre y tu poder / por toda criatura» de la paráfrasis dantesca del Padrenuestro (Purg. XI, 4-5) una referencia al Cántico de las criaturas de san Francisco? Dicha consonancia se presenta en el canto XI del Paraíso con un nuevo aspecto, que los asemeja aún más $(2021,8)$.

Así asimila el pensamiento del poeta al del Santo amante de la pobreza:

La santidad y la sabiduría de Francisco sobresalen precisamente porque Dante, mirando nuestra tierra desde el cielo, puede percibir la mezquindad del que confía en los bienes terrenales: «¡Oh insensatos cuidados de los mortales! / ¡Cuán débiles son las razones / que os hacen volar a ras de tierra!» (1-3). [...] Toda la historia o, mejor, la «vida admirable» del santo se basa en su relación privilegiada con la Dama Pobreza: «Mas para no proseguir en lenguaje demasiado hermético, / entiende que Francisco y la Pobreza son estos amantes / a los que me refiero en mi largo discurso» (73-75) [...] En el canto de san Francisco se recuerdan los momentos más destacados de su vida, sus pruebas $y$, finalmente, el acontecimiento en el que su configuración con Cristo, pobre y crucificado, encuentra la máxima y divina confirmación en la impresión de los estigmas: «encontrando a aquella gente demasiado reacia a la conversión, / por no permanecer ocioso / volvióse a recoger el fruto del huerto de Italia, / y en el áspero monte entre el Tíber y el Arno, / de Cristo recibió el último sello / que sus miembros llevaron durante dos años» (103-108) $(2021,5)$. 
Es de destacar como Francisco se detiene en la comprensión que Dante poseía del carácter de su Commedia:

Su poema, altísima expresión del genio humano es fruto de una inspiración nueva y profunda, de la que el poeta es consciente cuando habla de él como del «poema sagrado / en el cual han puesto mano el cielo y la tierra» (Par. XXV, 1-2) (2021, Intrd.).

El papa Francisco, cuyo pensamiento es siempre innovador, ve en Dante algo más:

En él podemos vislumbrar a un precursor de nuestra cultura multimedia, en la que palabras e imágenes, símbolos y sonidos, poesía y danza se funden en un único mensaje $(2021,9)$.

Agrega dos aspectos más de la obra dantesca: el haber descubierto y propuesto, a través de sus vicisitudes personales, la ruta hacia la felicidad y el uso de la con lengua popular para poder llegar a todos con un mensaje de alcance universal. Y ello sobrepasa las peculiaridades epocales y las diferencias de sensibilidad individuales.

Nuestro papa se pregunta si Dante posee actualidad aún y responde:

Dante hoy [...] no nos pide que sea solamente leído, comentado, estudiado y analizado. Nos pide más bien ser escuchado, en cierto modo ser imitado, que nos hagamos sus compañeros de viaje, porque también hoy quiere mostrarnos cuál es el itinerario hacia la felicidad, el camino recto para vivir plenamente nuestra humanidad, dejando atrás las selvas oscuras donde perdemos la orientación y la dignidad. El viaje de Dante y su visión de la vida más allá de la muerte no son simplemente el objeto de una narración, no constituyen un mero evento personal, por más que sea extraordinario $(2021,9)$.

\section{Y continúa:}

Aunque Dante sea un hombre de su tiempo y tenga una sensibilidad distinta a la nuestra en algunos temas, su humanismo aún es válido y actual y, ciertamente, puede ser un punto de referencia para lo que queremos construir en nuestro tiempo $(2021,9)$. 
Y Francisco recomienda que se dé a conocer a Dante más y mejor utilizando los medios a nuestro alcance haciendo "accesible y atrayente" a todos "el tesoro cultural, religioso y moral contenido en sus obras". Para ello han de empeñarse "las comunidades cristianas que conservan las memorias dantescas", las instituciones académicas, culturales y, especialmente, los artistas:

[...] para que den voz, rostro y corazón, que otorguen forma, color y sonido a la poesía de Dante, siguiendo la vía de la belleza, que él recorrió magistralmente; y que así se comuniquen las verdades más profundas y se difundan, con los lenguajes propios del arte, mensajes de paz, libertad y fraternidad. En este particular momento histórico, marcado por tantas sombras, por situaciones que degradan a la humanidad, por una falta de confianza y de perspectivas para el futuro, la figura de Dante, profeta de esperanza y testigo del deseo humano de felicidad, todavía puede ofrecernos palabras y ejemplos que dan impulso a nuestro camino. Nos puede ayudar a avanzar con serenidad y valentía en la peregrinación de la vida y de la fe que todos estamos llamados a realizar, hasta que nuestro corazón encuentre la verdadera paz y la verdadera alegría, hasta que lleguemos al fin último de toda la humanidad, «el amor que mueve el sol y las demás estrellas» (Par. XXXIII, 145) (2021, 9).

\section{Bibliografía}

Alighieri, D. (1994). La Divina comedia, bilingüe en Obras completas de Dante Alighieri. Madrid: BAC.

Archivio di Stato di Bologna e Sezione di Imola. Recuperdo de http://www.archiviodistatobologna.it/it/bologna/attivit\%C3\%A0/mostreeventi/gioioso-ritornare-dante-bologna-nei-750-anni-dalla-nascita/01bologna

Barbero A. (2020). Dante e il potere. Conferencia pronunciada el 16/10/20 en el refectorio de la Opera de Santa Croce para RaiPley. Recuperado de https://www.youtube.com/watch?v=Erp7CP7eflY\&t=2878s

Barbero A. (2020). Dante fra guelfi e ghibellini. Conferencia pronunciada el 20/5/20 en el Teatro Bellini di Napoli. Recuperado de https://www.youtube.com/watch?v=183UQkd6Wgs

Barbero A. (2021). Dante. Bari: Laterza. 
Benedicto XV, Papa (1914). Nobis, ad católica. Recuperado de https://www.vatican.va/content/benedictxv/it/letters/1914/documents/hf_ben-xv_let_19141028_nobis-adcatholicam.html

Benedicto XV, Papa (1921). In praeclara summorum. Recuperado de https://www.vatican.va/content/benedict-xv/es/encyclicals.index.html. [La versión española está disponible en Wikisourse]

Benedicto XVI, Papa (2006). Discurso a los participantes en un congreso internacional organizado por el consejo pontificio "Cor Unum". Recuperado de http://www.vatican.va/content/benedictxvi/es/speeches/2006/january/documents/hf_ben-xvi_spe_20060123_corunum.html

Boccaccio, G., (1365). Trattatello in laude di Dante, Recuperado de https://www.liberliber.it/mediateca/libri/b/boccaccio/trattatello_in_laude_ di_dante /pdf/tratta_p.pdf https://library.weschool.com/lezione/danteboccaccio-4488.html

Bruyne, E. de (1963). Historia de la estética, t. II, BAC.

Francisco, Papa (2013) Lumen Fidei. Recuperado de https://www.vatican.va/content/francesco/es/encyclicals.index.html

Francisco, Papa (2015) Mensaje al presidente del consejo pontificio de la cultura con motivo de la solemne celebración del 750 aniversario del nacimiento del gran poeta Dante Alighieri, recuperado de http://www.vatican.va/content/francesco/es/messages/pontmessages/2015/documents/papa-francesco_20150504_messaggiodante-alighieri.html

Francisco, Papa (2021) Candor lucis aeternae. Recuperado de http://www.vatican.va/content/francesco/es/apost_letters/documents/pa pa-francesco-lettera-ap_20210325_centenario-dante.html

Juan Pablo II Papa (1985). Discurso de discurso de la inauguración de la muestra Dante en el Vaticano. Recuperado de http://www.vatican.va/content/john-paulii/es/speeches/1985/may.index.html....

Juan Pablo II, Papa (1997). Palabras del papa Juan Pablo II al término de la lectura de un texto de la divina comedia de Dante. Recuperado de 
http://www.vatican.va/content/john-paul-

ii/es/speeches/1997/august.index.html

Mejía Rivera O. (2019). Dante Alighieri y la reveladora teoría sobre sus estudios

en medicina. WMagazin. Recuperado de

HTTPS://WMAGAZIN.COM/DANTE-ALIGHIERI-Y-LA-REVELADORA-

TEORIA-SOBRE-SUS-ESTUDIOS-EN-MEDICINA/

Mejía Rivera, O. (2019) Dante Alighieri y la medicina, Madrid: Punto de Vista

Editores.

Pablo VI, Papa (1965) Motu propio Altissimi cantus. Recuperado de http://www.vatican.va/content/paul-vi/it/motu_proprio/documents/hf_pvi_motu-proprio_19651207_altissimi-cantus.pdf

Petrarca, F. (1964). Canzoniere. Testo critico e introduzione di Gianfranco Contini Annotazioni di Daniele Ponchiroli Giulio Einaudi Editore Collana: Nuova Universale Einaudi, Ristampa 12, 1989. Recuperado de ttps://www.liberliber.it/mediateca/libri/p/petrarca/canzoniere/pdf/canzon _p.pdf

Pirandello, L. (1994). El humorismo, trd. de E. Aloisi, Buenos Aires, Leviatán.

Ravassi, Gianfranco (2015). "Dante e i Papi: Vangelo in poesía". Avvenire, 5/12/2015. Recuperado de https://www.avvenire.it/agora/pagine/dantee-i-papi 